How to cite: Caian, M., Radu, C., Bandoc, G. (2021) Changes in Breeze Warmest Summers for the Romanian Black Sea Coast in Climate Scenarios for the Time Horizon 2050. 2021 "Air and Water - Components of the Environment" Conference Proceedings, Cluj-Napoca, Romania, p. 149-158, DOI: 10.24193/AWC2021_14.

\title{
CHANGES IN BREEZE WARMEST SUMMERS FOR THE ROMANIAN BLACK SEA COAST IN CLIMATE SCENARIOS FOR THE TIME HORIZON 2050
}

\author{
Mihaela CAIAN ${ }^{1}$, Crina RADU ${ }^{1,2}$, Georgeta BANDOC ${ }^{1}$ \\ DOI: $10.24193 /$ AWC2021_14
}

\begin{abstract}
The study aims to analyze and compare the mean sea level pressure field to show the changes in the breeze regime in the coastal area of Romania in the current climate and the one projected in climate scenarios. The mechanism and variability of the breeze cell (intensity, location, frequency, persistence) are analyzed and compared for extreme conditions of warmest summers (July) during the two climatic intervals: 19712000 respectively for the RCP4.5 2021-2050 scenario. The high-resolution climate is simulated using the RegCMv4.5 regional climate model at $5 \mathrm{~km}$ resolution, coupled with the global EC-Earth model. These dynamical downscaling methods were performed for the first time for Romania in ANM (Meteo Romania) during the AZURE-Microsoft project (2018), aiming to refine the scale of the global climate scenarios to allow process analysis. The mechanism of changes is analyzed with the interaction between regionalscale conditions and large-scale dynamic factors. The results indicate changes in the frequency of intense events and the spatial development of the breeze cell, with a timemean intensification of both sea and land breezes and, a greater spatial advance in the area mainly during the day. Large scale-dynamics changes in interaction with the breeze circulation lead to an anticyclonic rotation under a warmer climate of the coupled circulation that induces a shift to the South-West of the cell, with a possible impact on the location of the associated precipitation. Regarding timing, a time-delay in the sea breeze occurrence (smaller pressure gradients persist longer due to warmer sea surface temperature), together with enhanced cell intensity, later on, makes the event appear as a more abrupt or extreme one. The results of the study provide potentially important input for further analysis of projected impacts of the breeze circulation on the regional climate.
\end{abstract}

Keywords: Romanian Black Sea coast, sea-land breeze, climate change, mean sea level pressure, RCP4.5 scenario

\section{INTRODUCTION}

Sea/Land breeze is described by wind (which blows from the sea to the land during the day and the opposite during the night) but also by the atmospheric pressure (which decreases in the convective zone of high surface temperature and increases in the cold, descending zone).

\footnotetext{
${ }^{1}$ University of Bucharest, Faculty of Geography, Bucharest email: crinaradu7@gmail.com

${ }^{2}$ National Meteorological Administration, Bucharest.
} 
During the warm season, especially in the summer season, the breeze has the highest intensity and frequency due to the presence of a significant thermal gradient between sea and land.

The study of the breeze is especially important from the perspective of the generated impact: the frontogenesis induced along the coast by these gradients can generate the formation of severe convection (Abulikemu et al., 2016; Bhate et al., 2016; Miller et al., 2003). The impact of breeze circulation can also be seen in the pollutant dispersion and photochemical smog genesis (Evtyugina et al., 2006; Mavrakou et al., 2012; Moussiopoulos, 1985, 1993; Moussiopoulos et al., 1995). Also, authors such as (Steele et al., 2015) studied the breeze and the importance of its influence in the production of wind energy.

In this study, we focus on extreme changes in the breeze cell, projected under climate change for the time horizon 2050 for the Black Sea coast of Romania, during the most critical conditions: the warmest summers (July). We use the mean sea level pressure field for this analysis, simulated under present and climate change conditions by the same modeling system (a coupled high-resolution regional/ global models' system).

The analysis of these simulations targets to assess information about the amplitude, frequency, time and space development changes, persistence, and impact of breeze on the regional climate.

\section{DATA AND METHODS}

\subsection{Data used}

For the first time, a climatic regional model was run at a $5 \mathrm{~km}$ resolution to produce high-resolution climate scenarios for Romania, resolution able to provide relevant estimates of the impact and to investigate processes mechanisms. The model used is RegCMv4.5 (Elguindi et al., 2014) and the runs were performed in coupling with the EC-Earth global models (Hazeleger et al., 2010). This coupled modeling chain was run for selected five warmest summers (July) simulated by the coupling model EC-Earth in each of the two intervals: actual (1971-2000) and RCP4.5 scenario (2021-2050) as shown in Table 1. We analyzed data for the month of July every three UTC hours ( $+3 \mathrm{~h}$ Romanian hour) to analyze the diurnal evolution of the sea breeze cell.

Table 1. Simulated 5 years for the warmest summer modeled by the global EC-Earth model during the actual period 1971-2000 and under the RCP4.5 scenario (during 2021-2050)

\begin{tabular}{|l|l|l|l|l|l|}
\hline Actual period: $1971-2000$ & 1987 & 1988 & 1997 & 1998 & 2000 \\
\hline RCP4.5 scenario period: $2021-2050$ & 2024 & 2027 & 2029 & 2045 & 2046 \\
\hline
\end{tabular}

\subsection{Software}


The RegCMv4.5 climate model was calibrated for very high resolutions. The dynamical downscaling of the EC-Earth global model using this optimized RegCM model configuration was performed on a cloud multi-processor environment (Azure Project, Microsoft 2018, Caian et al. 2019). The EC-Earth global model data were extracted from the CMIP5 database. All the post-processing for this analysis was written in Phyton language, the data handling used the CDO (Climate Data Operations) package and the graphics were performed using GRADS software.

\section{RESULTS AND DISCUSSIONS}

Fig. 1 shows the mean sea level pressure (MSLP) during the warmest summers (July) simulated for the actual period (HIST, lines 1,2), for the RCP4.5 scenario (RCP4.5, lines 3, 4) and their differences (scenario minus actual, lines 5, 6). For each line, the multiannual average of the warmest 5 summers at every 3 hours is figured.

For this study, we use the RCP4.5 scenario in the analysis because of its good relevance for the time horizon 2050 targeted here: the main differences between scenarios increase in time mainly after 2050, while a huge European and International effort are directed towards mitigating emissions and achieving a milder scenario of climate change before 2050 (COM, 2019).

Fig. 1 reveals an increase in the entire region of the MSLP field in RCP4.5 compared to HIST for all hours (lines 4, 5), especially for 09 to 12 UTC with a maximum increase in the West of the Black Sea, near the coast, corresponding to the initiation and development of sea-land circulation. We also observe a much more intense day-time breeze cell in RCP4.5 (with a significantly more important MSLP gradient at 12 UTC) than in HIST; the same intensification of the gradient in RCP4.5 compared to HIST is maintained at 15 and 18 UTC. The same gradient is weaker between 21 and 09 UTC which indicates a more abrupt "set-up" and development (so a phenomenon with a higher severity).

The cell's spatial extension is also increased: we observe the center of the daytime ascension is shifted towards the South-West in RCP4.5 (time 12, 15, 18 UTC; minima location is marked on maps), which is in agreement with an increased convergence and an increased intensity of the pressure gradients. Together with a NE-wards shift of the sea-maxima, the local circulation shows so an anticyclonic rotation of the breeze circulation in RCP4.5 relative to HIST, bringing the breeze circulation in RCP4.5 relative to HIST, bringing the breeze front to the South-West over land: this dynamic could be reflected in the associated precipitation field changes in the South and East of Romania.

The cause is the coupling between the breeze circulation and the large-scale circulation (high positive pressure anomaly in S Moldova - line 3) in the warmest years RCP4.5 compared to HIST, which agrees with projected increased amplitude of the very warm, higher latitude penetrations of Azores-Mediterranean origin 
anticyclone (a consequence of increased amplitude of the planetary waves already signaled in a transient warmer climate.
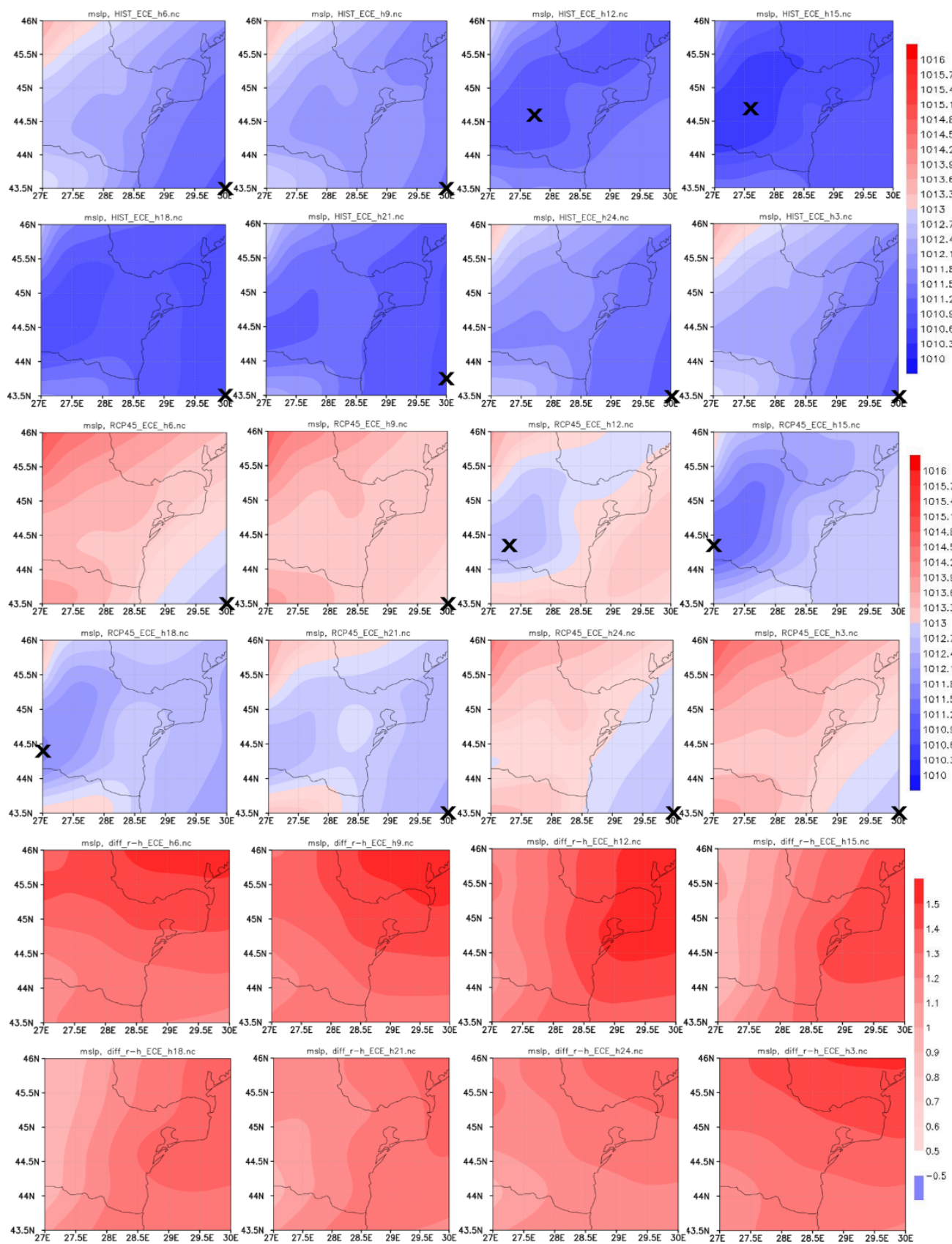

Fig. 1. MSLP - RegCMv4.5 coupled with E-Earth model, actual period (lines 1, 2 above), RCP4.5 scenarios (lines 3, 4 center), and the difference between scenarios-actual 
(lines 5, 6 below) - multi-annual averages of the July month, 06, 09, 12, 15 (associated with the sea breeze) respectively 18, 21, 24, 03 UTC hours (associated with the land breeze) (left to right); The sign " $X$ " indicates the position of the minimum value in the represented area

A longitudinal section of the diurnal evolution of the pressure field at passing the coast of Romania $(27-30 \mathrm{E}, 44.3 \mathrm{~N})$ was further used in the analysis. The section stretches for about $130 \mathrm{~km}$ on land and about $180 \mathrm{~km}$ at sea (Fig. 2).

In Fig. 3. the hours-longitudinal section shows a general increase of the pressure field at all hours under a warmer climate, with again a center of the ascendence in the day breeze shifted to the West and initiated with some delay compared to HIST but having a greater persistence and being so also longer-lasting during the day.

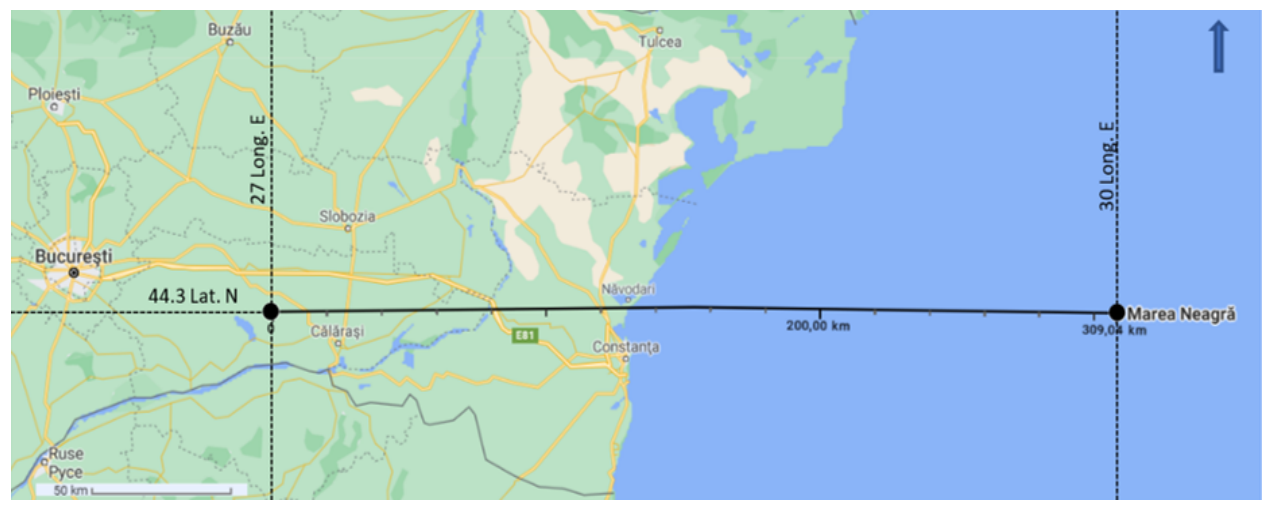

Fig. 2. Location of longitudinal section (27-30 Long. E, 44.3 Lat. N) used in Fig. 3 and 4 (source: Google Maps)
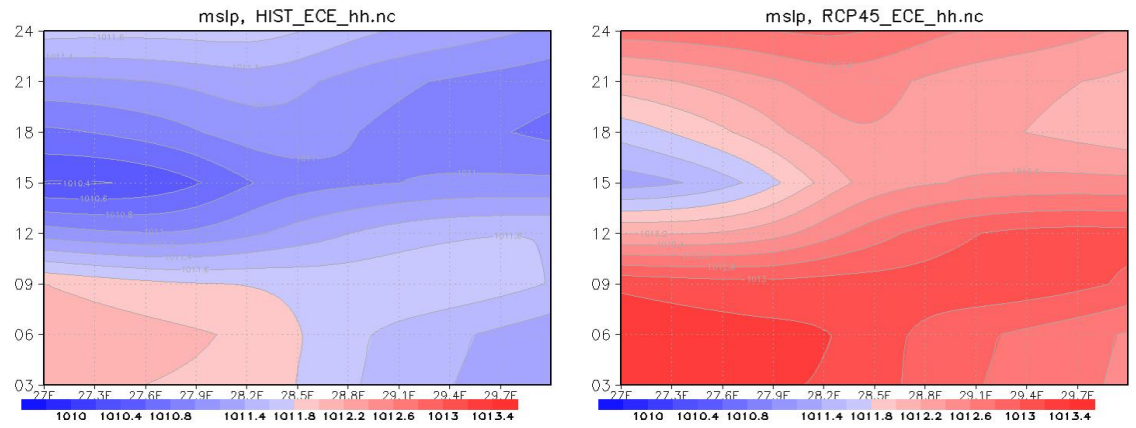

Fig. 3. Longitudinal sections - diurnal evolution of the pressure field - multi-annual average (warmest summers) for HIST (left) and RCP4.5 (right), lat-44.3N

(RegCMv4.5 model coupled with Ec-Earth); day-hours on Oy and longitude on Ox

First, Fig. 4 shows in a time-longitude section (latitude of mid-coast) a significant and increase in the frequency and intensity of the positive pressure gradient - diurnal in RCP4.5 (12, 15, 18 UTC), but also the tendency towards West (for a fixed latitude) of the maximum diurnal gradient shift- (highlighted here at 15 UTC), already signaled 
in Fig. 1. and Fig. 3; as well we note a significant frequency increase of the negative night-time gradient (land breeze) in RCP4.5 (marked on plots at 0, 3,6 UTC).

In terms of intensity, one can note the intensification of both cells with time (mainly during the latest years in RCP4.5). Comparing now the timing of the development (Fig. 4), this indicates a delayed start of the day-breeze cell but also its later maintenance. Persistence as hours mean-duration increases in the case of the evening (land) cell breeze, which appears and develops between 21-09 UTC in RCP4.5 The two changes in cell time-development and succession indicate a more abrupt change in the daily-cell circulation's occurrence.;

Regarding dynamics, the time-longitude diagrams in Fig. 4 also re-emphasize the orientation of the negative gradient center to the East (03...06 UTC) and of the positive gradient center to the West that coupled, support the anticyclonic rotation of the breeze circulation in RCP4.5 compared to the HIST already noted previously in Fig.1 warning on a potential impact on the regional precipitation shift during summer.

These results are in line with what was already noticed in previous analysis (Masouleh et al., 2019) as a signal in the last decades of the current climate compared to previous decades. Moreover, lastest years (1995-2010 compared to 1980-1995) indicated (same authors, in prep.) that evening breeze cell (land $\rightarrow$ sea) manifests an area enlargement and more frequent intense events in the last decades (1995-2010 compared to 1980-1995) especially at 18 UTC (21 local time), manifested by the extension of the negative pressure gradient (warm sea/cold land) above the Black Sea as well as by the initiation of the cell far deeper over the land. In contrast, here, for our particularly selected case of warmest summers, the day-time cell has a notable increase in RCP4.5 in the frequency of highly intense events as opposed to the mean result over the last decades of the current climate where: a decrease in the day-cell (sea $\rightarrow$ land) intensity in 1995-2010 (especially at 09, 12, 15 UTC) was noticed compared to 1980-1995.

Fig. 5 shows a time-series of pressure-gradients at a fixed coastal point (Mangalia). After 2021, the positive SST anomaly begins to have a noticeable impact: at all hours the gradient trends (night and day) are negative (black lines) as shown in Fig. 5.

Extreme gradients appear more frequently as expected, especially at night time (negative, yellow circles). Still, extreme, unprecedented values of positive gradients appear especially at 12 UTC, meanwhile, around 18-21 UTC we may note there are strong events with high persistence (that last for 2-3 consecutive days - thick red circle, Fig. 5), which indicates persistent heat-waves land, during these the warmest summers.

A merged analysis along the day is made in Fig. 6 that shows a time evolution (Oy) against daily-UTC hour (Ox) of the pressure gradient at a fixed coastal point (Mangalia). We note the appearance of time intervals with high persistence of the pressure gradient with no change in sign along the day (lack of breeze cycle) in Fig. 6 , which indicates possibly that the mean frequency of the breeze might decrease, 
but meanwhile with an increase in the frequency of severe and extreme breeze events (as shown above).
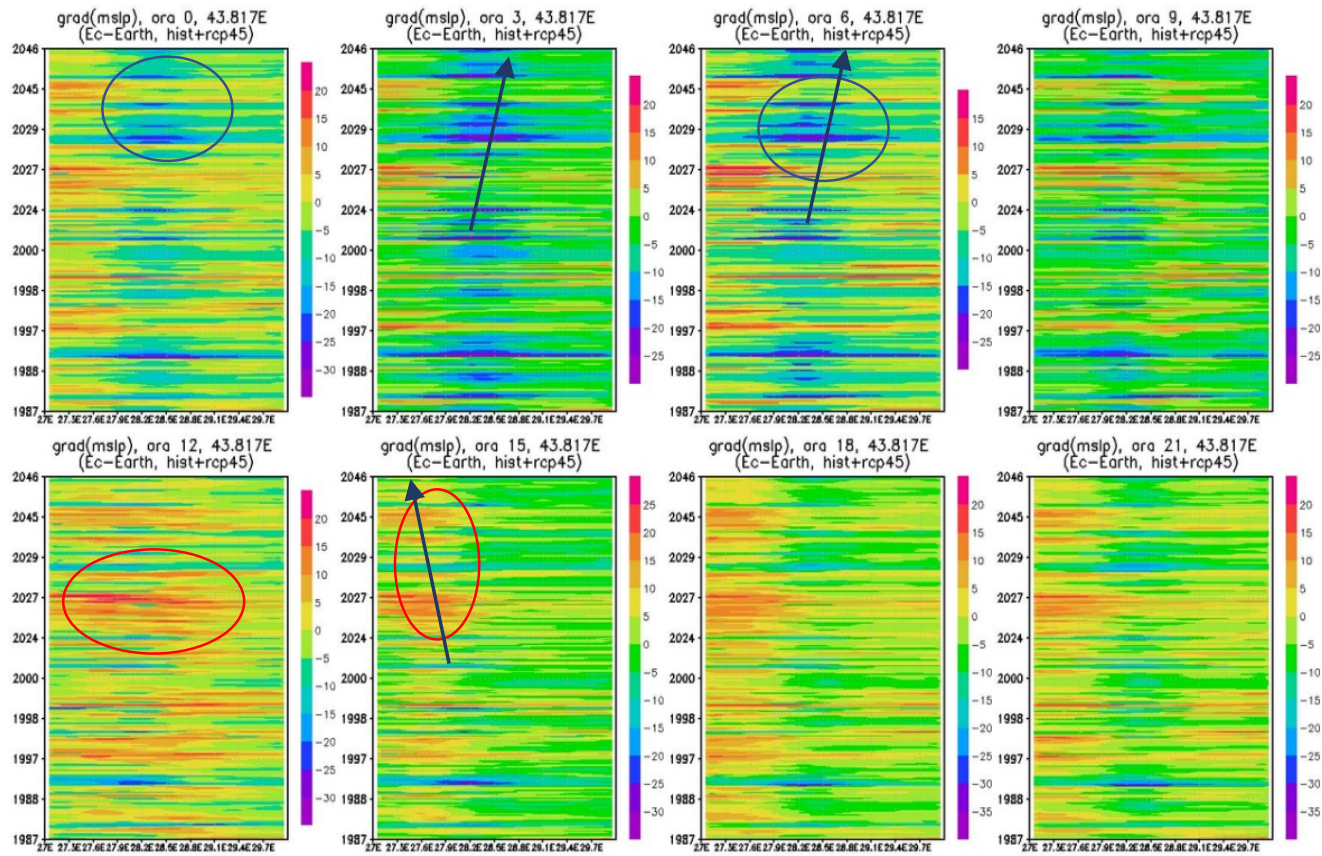

Fig. 4. Zonal gradient (Ox) for MSLP (coastal zone of the Black Sea, 43.8 Lat. N). The panels are for 00, 03, 06, 09 UTC hours (above) and 12, 15, 18, 21 UTC hours (below); HIST + RCP4.5 predicted warmest summers (years on $\mathrm{Oy}$ )
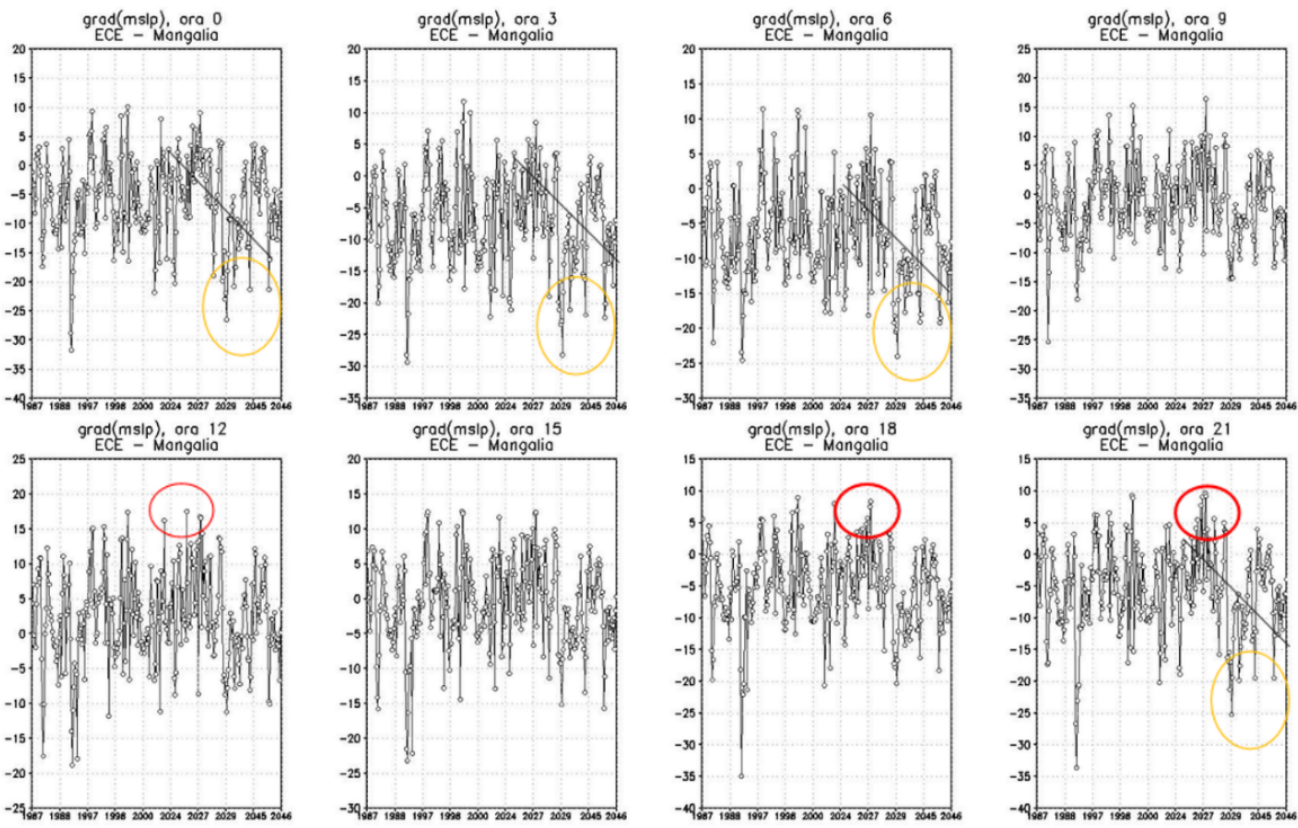
Fig. 5. Evolution of the zonal gradient of MSLP at Mangalia (28.35E, 43.5N); The panels are for 00, 03, 06, 09 (above) and 12, 15, 18, 21 (below). Specified time - daily, July, HIST + RCP4.5 warmest predicted summers years (years on Ox)

Although these results were analyzed on a downscaling modeling data-sets, they appear coherent from various analysis aspects, a fact that sustains their physical relevance.

To estimate the uncertainty of these results we need to extend the application of the developed analysis methodology to an ensemble of models. We already dispose of the high-resolution downscaling of the RegCM model coupled with MPI and HadGEM models that we will investigate soon. As well we intend to further compare these results to the CORDEX data basis (at $11 \mathrm{~km}$ resolution).

These results could show a final interest reflected in the impact of breeze cell changes that can be seen in the precipitation field and other variables of sub-regional and regional climate.

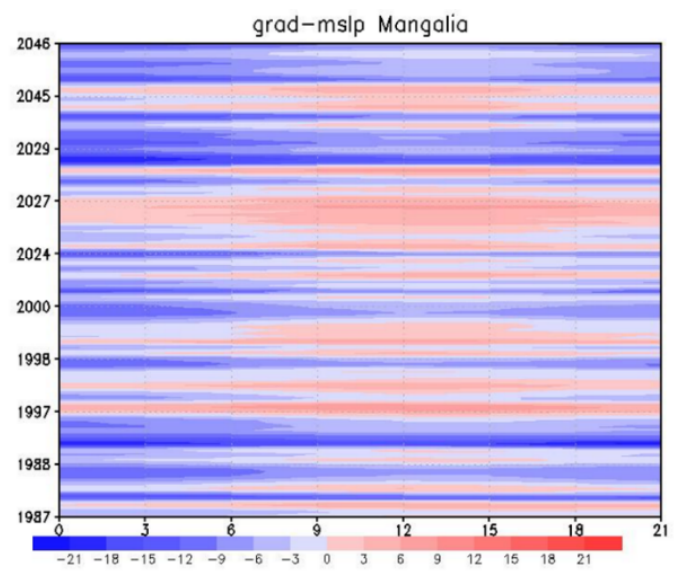

Fig. 6. Particular case: Mangalia, multi-annual average MSLP gradients for 00, 03, 06, 09, 12, 15, 18, 21 UTC for the warmest summer (July) in HIST + RCP4.5 simulated by RegCMv4.5 coupled with EC-Earth

\section{CONCLUSIONS}

We summaries the results concerning projected changes in the: frequency, intensity, day-duration and persistence, spatial extent, and regional impact of the breeze cells under a warmer climate of the RCP4.5 scenario, compared to the actual climate.

The warmest summers in the climate of the RCP4.5 scenario, regionalized through dynamical downscaling at $5 \mathrm{~km}$, show a tendency to increase the frequency of highintensity breezes, more enhanced for the day-time breeze. Otherwise, we note the appearance of time intervals with same-signed pressure gradient lasting for days (absence of breeze cycle), which indicates the possibility of an overall mean breeze frequency decrease but meanwhile with increased frequency of higher-severity events.

The intensity is higher mainly for the evening (land) breeze due to deeper, unprecedented values of the negative pressure gradient in the evening (associated to 
warmer sea surface temperature - SST), tendency accelerated in time (higher in the very last years of the scenario). There is also a tendency, but weaker, during earlyday (until 9 UTC) towards a decreased pressure gradient under RCP4.5 compared to HIST (Fig. 4) that is correlated with a "diurnal relaxation" of the pressure gradient (Fig. 1) and associated with the overall mean increase of the pressure during the warmest summers. In the interval 09-18 UTC, the pressure gradient associated with the breeze cell rapidly increases in RCP4.5 compared to HIST leading to a quicker (more abrupt) increase in intensity during the day.

Regarding the day-time cell, its extreme intensity rather preserves the range, while however, we note an increase in the persistence of extreme events (even up to several consecutive days) in RCP4.5 compared to HIST.

The time-development indicates a slight delay of the day-time cell' occurrence but with longer-lasting later in the afternoon (from 12 up to 21 UTC)., an increase that is also persistent. This, together with a time-expansion of the night breeze leads to a more sudden (abrupt) character of the day-cell occurrence and development, accelerated in time in RCP4.5 compared to HIST.

Regarding the impact of breeze changes on the regional climate, we identify a possible mechanism of sub-regional/regional climate teleconnection and impact. This relies on an anticyclonic rotation of the breeze cell in RCP4.5 relative to HIST, due to the interaction between large-scale and local circulation, with potential impact on the extreme variability of precipitation on a sub-regional scale mainly affecting in the South and East of the country.

\section{REFERENCES}

1. Abulikemu, A., Xu, X., Wang, Y., Ding, J., Zhang, S., \& Shen, W. (2016). A modeling study of convection initiation prior to the merger of a sea-breeze front and a gust front. Atmospheric Research, 182, 10-19. https://doi.org/10.1016/j.atmosres.2016.07.003

2. Bhate, J., Kesarkar, A. P., Karipot, A., Bala Subrahamanyam, D., Rajasekhar, M., Sathiyamoorthy, V., \& Kishtawal, C. M. (2016). A sea breeze induced thunderstorm over an inland station over Indian South Peninsula - A case study. Journal of Atmospheric and Solar-Terrestrial Physics, 148, 96-111. https://doi.org/10.1016/j.jastp.2016.09.002

3. Caian M., L. Oana, M. Adamescu, A. Dumitrescu, S. Cheval, C. Cazacu, C. Angearu (2019), High-resolution dynamical downscaling of extreme climate using RCPs and landcover scenarios over Romania. Proceedings of EGU 2019, Ref. no 17176-2 Vol. 21 (in prep. for subm.)

4. Elguindi, N., Bi, X., Giorgi, F., Nagarajan, B., Pal, J. S., Solmon, F., Rauscher, S., Zakey, A., O’Brien, T., Nogherotto, R., \& Giuliani, G. (2014). Regional Climate Model RegCM: Reference Manual Version 4.5. May.

5. Evtyugina, M. G., Nunes, T., Pio, C., \& Costa, C. S. (2006). Photochemical pollution under sea breeze conditions, during summer, at the Portuguese West Coast. Atmospheric Environment, 40(33), 6277-6293. 
https://doi.org/10.1016/j.atmosenv.2006.05.046

6. Hazeleger, W., Severijns, C., Semmler, T., Ştefănescu, S., Yang, S., Wang, X., Wyser, K., Dutra, E., Baldasano, J. M., Bintanja, R., Bougeault, P., Caballero, R., Ekman, A. M. L., Christensen, J. H., Van Den Hurk, B., Jimenez, P., Jones, C., Kållberg, P., Koenigk, T., ... Willén, U. (2010). EC-Earth: A seamless Earth-system prediction approach in action. Bulletin of the American Meteorological Society, 91(10), 1357-1363. https://doi.org/10.1175/2010BAMS2877.1

7. Masouleh, Z. P., Walker, D. J., \& Crowther, J. M. C. (2019). A long-term study of sea-breeze characteristics: A case study of the coastal city of Adelaide. Journal of Applied Meteorology and Climatology, 58(2), 385-400. https://doi.org/10.1175/JAMC-D-17-0251.1

8. Mavrakou, T., Philippopoulos, K., \& Deligiorgi, D. (2012). The impact of sea breeze under different synoptic patterns on air pollution within Athens basin. Science of the Total Environment, 433, 31-43. https://doi.org/10.1016/j.scitotenv.2012.06.011

9. Miller, S. T. K., Keim, B. D., Talbot, R. W., \& Mao, H. (2003). Sea breeze: Structure, forecasting, and impacts. Reviews of Geophysics, 41(3). https://doi.org/10.1029/2003RG000124

10. Moussiopoulos, N. (1985). A numerical simulation of the sea-breeze in Athens. Pure and Applied Geophysics, 123(2), 314-327.

11. Moussiopoulos, N. (1993). Athenian photochemical smog: intercomparison of simulations (APSIS), background and objectives. Environmental Software, 8(1), 38. https://doi.org/10.1016/0266-9838(93)90003-Z

12. Moussiopoulos, N., Sahm, P., \& Kessler, C. (1995). Numerical simulation of photochemical smog formation in Athens, Greece-A case study. Atmospheric Environment, 29(24), 3619-3632. https://doi.org/10.1016/1352-2310(95)00199-9

13. Steele, C. J., Dorling, S. R., Von Glasow, R., \& Bacon, J. (2015). Modelling seabreeze climatologies and interactions on coasts in the southern North Sea: Implications for offshore wind energy. Quarterly Journal of the Royal Meteorological Society, 141(690), 1821-1835. https://doi.org/10.1002/qj.2484

14. COM (2019) 640 final, The European Green Deal, Brussels, 11.12.2019

15. *** AZURE-Microsoft project (2018), Meteo Romania 